\title{
How Ideas Turn into an Active Force in Society
}

\author{
Abdallah Hidri \\ Qatar University, Doha, Qatar \\ Email: hidri.adam@yahoo.fr
}

How to cite this paper: Hidri, A. (2019). How Ideas Turn into an Active Force in Society. Advances in Journalism and Communication, 7, 1-18. https://doi.org/10.4236/ajc.2019.71001

Received: December 17, 2018

Accepted: January 19, 2019

Published: January 22, 2019

Copyright (c) 2019 by author(s) and Scientific Research Publishing Inc. This work is licensed under the Creative Commons Attribution International License (CC BY 4.0).

http://creativecommons.org/licenses/by/4.0/

\begin{abstract}
The Most prominent feature of social media and personal blogging websites is that, with their advanced and flexible nature, they are now media under the management of social individuals all involved in the sensmaking and reality shaping processes and remain thanks to their design of the communicative environment with the greatest influence on the techno-social activities of society. Given the fact that this environment was distinctive from its early days with a strong flavor of individualism-through language mostly-it actually brought back the romanticism of the 18th century that swept across the fields literature, arts and philosophy and dragged it right to the center of the media focus declaring a veritable revolution against the ways of the classic institutionalized media ruled by the standards and the ethics of media. Social media are now considered the effective drive of crisis management and the true vehicle of the public opinion as it would appear form social and political events façades, as it would be-for instance-in the case of the Arab Spring, or the events of July 2016 Turkish failed coup d'état. But how again? How social media could be the media environment on which ideas could turn into an active force of society?
\end{abstract}

\section{Keywords}

Actor Network Theory, New Public Sphere, Social Media, Polarization, New Media, Public Opinion

\section{Introduction}

The undivided attention accorded to the social media's role debating and dealing with all sorts of the public concern issues and exerting its influence on the public opinion industry seems to be the prominent concern featured on most of the media and communication research papers, for the social action as defined and theorized by Maximillian Karl Weber, remained constrained by the communicative functions granted by the social media networks. 
Those communicative functions hurled the internet down the pit of social concerns and appeared as the drive which dragged to light individuals' role to build and then reshape their own lived reality or as defined by Karl Weick as "the vital role of individuals to shape and react to their environment".

it would be fair to assume that the fascination with the ground-breaking progress of the interactive systems technologies is another reason for the focus on studying the social networks, a fascination akin to that which was noted at the dawn of cinema and radio and their powerful undeniable influence, as it was believed back then that mass media wielded a unique and a direct influence on people's behavior, those beliefs came to be known as the Magic bullet theory.

This trend of fascination with the media and communication technologies is coming back today to cast its vast shadows on the literature of Media and Communication establishing functional constructivism as key to decipher most of the "combination reactions" occurring on the internet. These reactions are often narrowed down to a dual between self-actualization and "defining the facts", facts definition remained a mission undertaken by an institutionalized industry spearheaded by the conventional mass media channels for decades. Struggle and Change here are the key elements to take into consideration when thinking of social media networks.

Whether the matter involves blogging as the medium for publishing a biography, conveying ideologies, discussing politics and economics-or even the data leaks to bring to light the buried secrets of the world global policies, exposing the deviations of political affairs and international relations, or perhaps social media networks such as Twitter, Facebook, Myspace or Instagram, the purpose of all social media, as a whole, remains, first and foremost, the free expression of opinions and the contribution to the public affairs as much as it suits the users-contributors-of the social media networks. The struggle to bring reality together by the search of meaning, the state of "hyper reality", as described by Baudrillard, Lyotard and the pioneers of the Critical theory, the state of a "simulated" reality (Adorno, \& Horkheimer, 1944).

And as the nature of the Social media is that of struggle and change, it would not be understandable, as far as the field of sociology is concerned, through the lenses of structural functionalism as a social theory promoting solidarity and stability between parts of a complex system. The social media is a standalone individual dynamical environment taking hold within a larger and public environment, its application seems to be within the reach of anyone with minimalistic digital aptitudes thus it is bearing the seeds of Chaos, Chaos as it is defined by the laws of physics.

Everything that happens within the boundary of its vast network as a series of complex ever-evolving communicative operations is in fact the embodiment of a never-ending random behavior beyond exact measure, it cannot be contained by simply altering the system: this new environment called "new media" is actually designed to wield Chaos as a complex dynamical tool harboring all sorts of unstable behavior. Chaos, hence, is an integral part of this nonlinear unpredictable 
and uncontrollable environment. The study of Social media networks remains beyond the rules that govern stable phenomena, which are completely understandable via the conventional scientific methods.

\section{New Public Sphere}

Sensmaking remains the gravity center of the social media networks which pulls everything around it from broadcasting to the sharing and the interaction to every set of meaning being produced: this production of meanings takes a singular curve spiraling down the center of "the Self" and the exploration of the ego as a way to achieve self-actualization producing multiplicity and difference while countering at the same time the ways of dominance and tyranny in society.

It is of note that everything that happens across the social networks from interactivity or intersubjectivity happens through Language, which stands as the appropriate exemplar space to establish a communicative reasoning based on intersubjectivity (Kant, 1993).

That's because Language shows a certain "flexibility", quoting Abdel Slam Al-Masseddi (Al-Masseddi, 1986), which permits both clarity and ambiguity, producing both accord and discord, giving floor to practice both admission and disregard, accomplishing both Foregrounding and concealing, a flexibility that allows as it is known in Linguistics: the creative language Management. For Language possess the feature of dual-Pattering also known as double-articulation, (Fakhoury, 1990).

It is of no doubt that all the approaches, regardless of their theoretical and epistemological differences or nature: philosophical or otherwise, recent ones or old, come to term that language is a field of communication and an area of understanding.

Language as perceived by Martin Heidegger, in its valuable connection to his central cause: the cause of the "Being" and its nature is "the house of being, in its home man dwells." or as it is seen by Charles Sanders Peirce who regards everything as signs: an existence in both place and the non-place. Leonard Bloomfield suggested that Language is a verbal behavior while Jacques Derrida considered Language the center of the very Existence for it is only with Language Existence may be deciphered and thus we see him preaching about bringing Language under new lenses where reality is viewed through a set of several rhetorical masks: Language establishes our very perception of the world, a cornerstone of science, philosophy and metaphysics (Abdullah, Al-Ghanmi, \& Awad, 1990), an endless Sequence of different senses that must be put to use without restrictions.

Jürgen Habermas calls it in his Theory of Communicative Action “...a medium of communication that serves understanding..." so He regards Language as the foundational component of his model of human communicative action and according to him Language-common and everyday language specifically-is the appropriate communication sphere for dialogue and expression (Hidri, 2012).

What is important about language when talking about social media is that, 
aside from being the center of existence, a field of communication and a space of Understanding, it is the main source of nourishment for the semantic layer, in which occurs the social action. And here lies the real gravity of social media for their presence as a new public sphere and being as a middle actor in forming the semantic layer that is generated by the language, because this layer is like the insight that leads to the awareness of the social issues. And according to this layer, ethical and moral values are determined.

The question that we make is to which extent this new public sphere, represented by social media, can be considered as a determinant factor in building the general opinion, especially that the world's internet users' rates are getting higher every day? (Web Marketing Conseil Report 2016).

Is the increased presence of social media networks in people's lives a mere technological inevitability as predicted out by Marshall McLuhan? Or is it rather an active flow in the current of social change decisive of its course? are social media the core reactor of the social action as it would appear from the social and, especially, political events such as the tide of Arab Spring that has propelled itself in the form of protest movements witnessed by some Arab countries in the beginning of 2011 under the influence of the Tunisian revolution that broke out in late 2010 and toppled the regime of former President Ben Ali, or the failed Turkish coup d'état attempt of July 2016 which disturbed the political climate both domestically and internationally? Is it safe to assume the social media networks a media environment turning ideas to an active force of society?

The answers of these research's questions are tied to the better understanding of social media networks inner machinations and its very nature as an environment, which within its boundaries the social action takes shape. Which leads us as well to lean closely on the Chaos Theory: the very branch of mathematics focused on the behavior of nonlinear dynamical systems, which coalesced in the 60 's of the 20th century.

The answers of this research shall also call upon a better understanding of the Actor-Network Theory as the theoretical and methodological approach to the social theory which posits since it development in the early 1980s that objects, ideas, processes, or any other relevant factors are seen as just as important in creating social situations as humans; this might leads us to a better understanding of the role of social media networks in shaping the public opinion and keep us as well from sidetracking to the classical approaches of the social sciences such as the social progress theories, the Social cycle theories or even the Structural functionalism theory, as they are, for the large part, standardized theories that do not take Chaos into consideration as a component of the social action and the motion of evolution and progress.

Our focus on the chaos theory is very crucial when it comes to research social issues generally related to the new media, as we have explained several times, (Hidri, 2012), the necessity to reference the chaos theory principles after squeezing out its mathematical essence: for the current subject of the research is 
involved around the study of the social behavior which happens within a nonlinear dynamical social structure, a conveyor of the nonlinear dynamical systems infused with chaos as chaos is defined by physics.

The reliance on Action network theory is justified by the fact that societies are now living an ever-changing and unpredictable world, a world that allows an individual-[level] situation to shape shift into a global phenomenon, the local event to an international one, and vice-versa.

Thus, the best understanding of the morphology of the social action-which remains actively the result of various heterogeneous factors within a dynamical, multi-component, complex structured network, is bound to the understanding of the inner workings of both the main and secondary networks from which itthe social action-coalesced.

The Action-Network theory reveals then the path dependency of how exactly a non-significant simple state turns to be a state of powerful attraction with a significant mediatic influence.

\section{From a Paradigm of Control to a Paradigm of Polarization}

The most important and notable features of the social media networks and the personal blogging sites-thanks to their flexible and technologically advanced nature-that they are now a powerful public media tools in the hands of individuals:

The researchers consider this state of "personal" public media (Castells, 2006), as a new public space" a comeback to the romanticism of 18th century that swept across literature, Art and philosophy dragging it to center of the mediatic scene and declaring a veritable revolution against the ways of the classic institutionalized media which is defined and bound by the standards of media ethics, thus, paving the way to a new era of sensmaking, interpretation and decoding, countering and bringing down the very pillar of tyrannical-mediatic-sedimentation.

The flow of the late 18 'th century romanticism begun in its infancy as a movement thirsting for freedom, blinded by fantasy, vehemently denying rationalism and the classic principles derived from the ancient Latin and the Greek views. A new current of thoughts distinguished by a strong overflow of individualism embodied most strongly by language. Romanticism as defined by its early pioneers (Novalis, 1975: p. 66), is the movement of flight, the breaking of the fetters of reason and space for, according to them, man is nothing but a being of isolation, sadness, anxiety and primal fear and so to break free and achieve his inner peace, a man is to let loose of his spontaneous emotions and feelings, to express his affections and to share both his personal experiences and that of his society and era instead of bending his will to the rational binds that obstruct the truest picture of existence.

Romanticism from this scope is then considered a sharp tendency towards originality and individualism, the self-proving, establishment of identity and nationalism, a tendency that was brought to light by the philosophical and political 
works of the Jena Romantic group: Novalis, Fichte and Schelling among others; works that emphasized that the "ego" is the founder of creativity, a creative force on its own right (Hidri, 2012: pp. 88-89).

Romanticism of the new media which is quite apparent judging by the expansion of the personal-public media circles is characterized by the fall of most of the public ideologies, the victory of the "private" over the "public" and the deep criticism of Humanism (Aafia, 1998). an environment where everything moves as if it is a separate independent entity; rejecting the ways of dominance and always opposing exclusion, which was imposed by the institutionalized media, in all its forms.

So if the early 18 'th century Romanticism was a revolution against the philosophical rationalism and the classic forms of order and control then the 21st century romanticism is, in a way, a revolution against the mediatic rationalism that generated various forms of political, economic and cultural dominance and laid foundation for the reality of exclusion in the people social existence which was obscured by the institutionalized media in exchange for a production supposedly "built" to "serve" progress (Hidri, 2012: p. 92).

In contrast to the basic function of the institutionalized public media which is "Control" from a social standpoint as perceived by the works of Harold Lasswel, Robert King Merton and Paul Lazarsfeld in their definition of the public media functions, the primary function of this personal-public media: social media, blogging or other websites, is actually attraction or Polarization: to lure a maximum numbers of internet users and the followers of its informative or non-informative content for all the intellectual motions of the social individuals within the vast network are established through the drive of a Sense of Community in a way that binds all forms of linguistic communication with all its features and descriptive, informative, perceptive and poetic functions

It is indeed a brand-new design of mediatic, cultural and scientific production, editing exchange and interactivity, a design with patterns shaped by the ever-increasing need of internet users to communicate, to learn, to exchange, transcend and their pursuit of Self-actualization.

This sense of community is the social context, in which presence, Polarization - as a collective-individual phenomenon derived from the interaction between social individuals-is reinforced. Social psychology experts peered on this phenomenon and explained that it takes shape mostly as people tendency towards defending and identifying themselves with controversial decisions as well a tendency to call for unusual and unprecedented measures in sharp contrast to what is formal and generally socially approved (Moscovici, 1984: pp. 216-217).

From this scope, Polarization derives its meaning from the cultural diversity allowed within the very system of production, free exchange of meanings granted by this personal-public media as the social media users are not only spreading their own views, portraying their ideas and identifying their positions about everything from specific local and private matters to those of public con- 
cerns but also interacting with their peers' views and ideas. This happens in a way that defines the purpose of the communicative action as attraction and attention-raising, which means that the communicator-here the social media user-is an important pole-a relay really-of the massive complex nonlinear communicative network on the internet. So, if the purpose of mass communication within the institutionalized media remains control from the social and political standpoints then the primary objective of personal-public communication is polarization as defined by both the laws of physics and social psychology.

Social networks user's attitudes could be further observed to get a glimpse of their meticulous efforts in garnering the attention of a maximum numbers of their fellow users and subscribers and harvesting the "likes" regarding everything they share and publish, the higher the numbers of the "likes" or "tweets" the more popular the user, who becomes this way, an important symbolic beacon-very much like a magnetic pole-granting them an undeniable mediatic powerful influence capable of shaping the public opinion.

So, the weight of opinions and ideas strewn across the social networks is actually measured by the magnitude of their authors 'power of attraction regardless of the quality or the integrity of their content or even their conformity to ethics or polite and considerate speech.

Since the news industry, within this ever-changing semiotic environment is primarily a personal-public industry based on a semiotic structure and depending on the diversity of views and backgrounds in shaping reality is it not required to examine these complex networks with the lenses of the communication functions? let's us ask what is really happening at each internet user 's level whenever thoughts are formed, whenever an event is captured, whenever an opinion or statement are made or published with all their denotative and connotative significations as framed by the emitter-or Sender-himself and with the very sense meant by John Fiske (Fiske, 1932).

Given that, this emitter is but one of six models described by Roman Jakobson in his communication structure, the other models being: The Message, the Receiver, the Channel, the Context and then the Code Language. So would every user have an assimilation to the figure of speech he is about to produce or receive and a bundle of rhetoric tools by which to translate this assimilation and would every user have an objective context and another subjective one conditioning the sensmaking layers and the spheres of interactions and their echoes and if we would note that every message and text injected into the web are bound to be intertwined producing limitless effects on the sensmaking process: meaning production, exchange, reading (reading is always considered as a reproduction of meaning) and if we would acknowledge the dazzling speed with which these messages and texts are being sent and exchanged within the cyber space and if we would come to acknowledge all the components of this nonlinear communication landscape and its complex reliefs we would come to realize the astronomical size and number of variables governing this nonlinear communi- 
cation system making the process of featuring all its specifics nearly undoable and the prediction of which direction they would take effectively impossible.

This how exactly Chaos's nature is revealed: first as one's inability to link all the components and circumstances leading to a big event within an ever-changing dynamical system and second as the impossibility to study their structure, significance, their contexts and the degree of their complexity. Who could have predicted that young Tunisian Mohamed Bouazizi's self-Immolation in December 2011 would lead first to the toppling of Ben Ali's regime and then to become the catalyst for the Egypt Revolution and the overthrow of Hosni Mubarak later? Events raced back then in what would appear, as a strike of a random behavior known to be "chaos" in the dynamical systems for the human mind is unable, as we indicated, to discern the initial conditions and to grasp the fractals that would lead to huge outcome within a dynamical system such as the internet.

The question now is what is the nature of the catalyst within this chaotic communicative system that turns a random event to a social big polarized event: how exactly these little events course through the veins of this communicative body to be shaped into a public concern matter that would draw the attention of the public media influential figures?

Is social media the new influential pole that would dictate the agendas of the classic media and reshape Actuality?

\section{The Actor Network and the Public Opinion}

Many observers and researchers (Lam, 2012), come to believe that the revolutionary wave known as the "Arab Spring" would never take hold would it not for the role played by the social media such Twitter and Facebook in mobilizing the public and marshaling their users efforts towards demonstrations and the cause of social justice. Those assumptions are founded on the ground of the significant impact of social media use and the fascination with technical and scientific leaps of the media and communication technologies the same fascination indicated above and witnessed with the emergence of television and cinema back in an era when psychology established that people are a collection of homogenous human begins which could be subject to influence from a single source.

The state of this "Arab Spring" which centered the social media in the focus of the intellectual and scientific concerns as never before is primarily a state of deep change of the social conciseness which emphasized on the values that would secure democracy and social justice.

This deep change was the culmination of various conditions as it is the fact in every social change. Some sociologists (Durant \& Weill, 1997), categorize these conditions as rational conditions as would Max Weber (Weber, 1964), see them as the determining conditions of the social and civic change while others most notably Émile Durkheim links them to the population density's level as he would often emphasize on population growth as one of the main tributaries leading to the social and behavioral change and fusion (Durkheim, 1893). 
Others historians and philosophers and sociologists such as Lewis Mumford, (Munford, 1950) consider that technology is the actual catalyst of social and civic change in contrast to others sharing the views of Karl Marx that the catalyst is rather the simple old and plain class struggle going as far as to theorize humanity's entire history is nothing but a cycle of class struggle.

While the subject of the social change is actually an old ever-renewed intricate matter giving the blurry boundaries between its sociological, anthropological and philosophical approaches, we shall take it, for the purpose of this research paper, as a granted historical given matter, a public fast wide-spreading phenomenon taking shape thanks to the interaction of various heterogeneous factors of materialistic, symbolic and even human nature woven into the network that would generate both the change and evolution tide.

Ibn Khaldun glimpsed the nature of this Influential Network when he shed lights on the nature of tribal society evolution, and then again, he broached the subject in the context of explaining the inaccuracies committed by most historians of his time and their blatant disregard of the simplest rules of scrutiny when dealing with narrative information even though this particular context serves history more than social change theories so and when Ibn Khaldun stated:

".... Therefore the scholar of this Field (the Field of Historiography) needs to know the principles of politics, the nature of existent things, and the differences among nations, places, and periods with regard to ways of life, character qualities, customs, sects, schools, and everything else-He then further needs-a comprehensive knowledge of present conditions in all these respects, compare similarities or differences between the present and the past or distantly located conditions - he must know - the root causes of the similarities in certain cases and of the differences in others. - He must be aware of - the differing origins and beginnings of the various dynasties and religious factions, as well as of the incentives that brought them into being and the circumstances and history of those who supported them for him to have complete knowledge of the origin of every event..." (Ibn, n.d.: p. 59).

The meaning of this statement is strongly recommending that the complex network approach is the actually the one to be considered the most accurate when it comes to deal with and/or examine the social phenomena.

And while Ibn Khaldun was firmly foreboding about the simple fact of conveying narrative information and the disregard of the Truth he also emphasized on the comprehensive knowledge of the various complex root causes which lead to the facts and social events and the tide of social change.

He even went as far as to produce a rich collection crimped with both material and symbolic expressions denoting origins, customs, ethics, the principle of politics, nature of civilization and the human, psychological aspects, temporal and spacial dimensions, all are elements of a larger complex, dynamical network narrowed down by Bruno Latour, Michel Callon and Madeleine Akrich as the Regulatory and normative, physical and humanitarian factors influencing the 
social action (Ibn n.d.: pp. 59-60).

It is of note in this context to be reminded that most of the contemporary social theories which garnered quite a success and spread wildly across the field of media and communication in particular and the social and human science in general like the Actor Network Theory (Latour, 2007), are actually stemming from Ibn Khaldun theories which we consider the very core of the Actor network theory a fact that is apparent every time we come to understand the collection of expressions upon which "the Muqaddimah" is built, expressions including-but not limited to-: history, civilization, "Assabiya” or social cohesion, rulership, the state, social organization, ethics, trades and science (AlSayed, \& Hidri, 2006), the very elements composing the actor network and from their better understanding an explanation the social and intellectual change phenomena would be possible.

Actor-Network Theory is a sociological approach developed from the 1980s by a group of sociologists around Michel Callon, Bruno Latour, Madeleine Akrich to study the birth and development of spheres of influence. According to Michel Callon, "The Actor-Network Theory, which was developed to study science and technology and how it is born and spread in society, adds all the missing material elements to the theory of social networks" (Callon \& Ferrary, 2006: pp. 37-44), This is a theory, which shows how things work.

If we are to lean closer on the current event swirling around the globe, the significant ones and the small and if we are to focus on the various cases of social change which are spreading quite fast thanks to the near instant far reaching exchange of information across social media what would be prominently apparent is at first the technological aspect given the role social media of spreading the news and ensuring a maximum number of interactions between users of this personal-public media whilst the human and social aspects defining the actor network would appear nonexistent which means simply that our own perspective of the events are quite narrow and excluding the social structure, civilization, the social cohesion, rulership, the state and ethics which are the very human material and symbolic foundations of the very network around which the event coalesced and the very conditions of the intellectual and civic change.

If we are to recall the 15 of July 2016 Turkish failed coup d'état, while the focus was on the central role of the media technology which gave the Turkish president Recep Tayyip Erdoğan the opportunity to reach to his people and mobilize them to oppose the efforts of the rebel insurgents and defend the state's democracy and existence, the social, political, ethical and civic aspects which are the parts of the complex structure welded together as the central network around which this event occurred remained elusive.

Erdoğan took advantage of the renowned FaceTime Application during the time the insurgents took effectively the reins of the official national Turkish television $T R T$ to call upon the Turkish people to take to the streets and defend "democracy" and bring the rebels to justice. 
Back then the Turkish people actually answered the call effectively thwarting the coup d'état.

At first glance, the coup failed thanks to an effective use of the social media. This assumption has quite the logical counter argument, which is: were it not for the social media, which was to Erdoğan an effective "mediatic" refuge, the coup d'état would likely have been successful.

This assumption is strongly based on the real, deep and powerful effects of social media networks on the public opinion but ignoring the human, social and ethical aspects of event would be quite misleading and would lead surely to a deep misunderstand of what really happen back then.

We are refereeing here to intellectual and political maturity of those who answered the call and thwarted the coup. We are also referring to the ethical political stance of the Turkish opposition especially that of the secular opposition quite know for its fierce aggressiveness towards the Justice and Development Party.

The Turkish opposition took, back then, a firm stand defending the country's democracy and was known to make all bets on democracy on more than one occasion even if it was purely out of political interests.

We are also referring to governing party: The Justice and Development Party: the very same party upholding the modern Turkish minds points of view and pulling to its spheres many of the Turkish political factions, the party that, according to many observers, garnered the trust of the Turkish people and was successful in achieving quite a noticeable economical leap (Gul, 2015).

We are also taking note of the fact of the greatly reduced political influences of the Turkish military institution for more over than a decade and a half out of both local concerns and regional ones most notably those of meeting the requirements of the Turkish state to be part of the European Union which stipulates neutrality of the military institution and keeping it out of politics.

This is actually the sociological framework giving explanation to the actor network:

The very theory, which we assume the one to bring an end to the legendary status of social media as a personal public media targeting exclusively the public opinion. This legendary status is put to question through a thorough examination of the timeline and the path or "breadcrumbs" of the above-mentioned incident that would also reveal to us that the insurgent rebels made use-in their turn-of the social media in their attempt to depose Erdogan and took over, briefly, the national Turkish television: one the most important international news channels in Turkey through which the rebels issued their statement of the military seizing power, yet still despite of their logistics and mediatic preparations, the rebels coup d'état failed indicating the limits of social media and the mass media in general in bringing about a firm conclusion regarding the great social political and the public opinion matters.

In other words, we are saying that events do have a complex socio-cultural 
tissue often hoisted by media as a banner to appear before all, it is this "fluttering banner" in its nature an integral part of the complex network is the one that gives the public the impression that whatever happens as influences on the public opinion is actually caused by media, since media thanks to its technological and artistic eloquence and instant far reaching spread when putting events in the foreground is actually at the same time concealing the elements of the larger network which are the root cause of those very influences on the public opinion.

Hence even though the social media would appear as a near instant medium of information exchange the strongest foundation upon which Erdogan successfully thwarted the coup it is not actually in itself the root cause of the coup's failure.

It is in fact nothing but one of many foundations contributing to the event, it just appears as so, only because it is the technical and social vehicle of the event which is why we observe that many media and communication key figures and even then, some of the analyses take for granted the powerful influence of FaceTime application on the Turkish public opinion and consider it even the real stirring power of their interactions and opposition of the coup (Jabbar, 2016).

\section{Social Media Networks: From a Linear Velocity to an Exponential Velocity}

It is unwise to underestimate the role played by social media networks and the mass media in general in resolving global concerns, conflicts and mass mobilization given its mediatic and sociological aspects yet it is also unwise to overestimate it.

If we come to understand that despite social media capabilities to mobilize and redirect the public opinion and settle crucial matters not to mention its rhetorical mediatic nature it is after all emerging from a complex reality overflowing with the very same conditions allowing the success of such mobilization and conflicts settlements and even public opinion shaping.

Why, -for instance-when invoking the events of May 1968 in France we observe the lack of the mediatic role of the secret typed pamphlets, which could pass, back then for the emails exchanged across internet by today standards? after all the typewriting machine was a source of much annoyance and concern to the established political power as much social media is nowadays the thorn in the side of most of the current political regimes.

However why, on the other hand, whenever it comes to debate the events of the "Arab Spring" or any other global event such as Turkey's Coup d'état the social media seems to be exclusively garnering the attention of the analysts and the observers of the public concerns while the material, symbolic and socio-cultural factors leading to the very success of these social media in fulfilling their communicative functions appear to be discarded?

Let's explain the differences between these two cases by investigating the speed-or velocity-by which these influential media capable of turnings idea 
into a force of society run

The first case, we observe that the velocity of information exchange via typed pamphlets is quite negligible, we observed in much earlier context that is quite comparable to the limited speed of the courier and since it is limited, the focus remained centered on the levels of the social consciousness or rather the Student activism that opposed the negligence policies imposed by the French government back then and its colonial and imperialist regime and the student activism denouncing the Vietnam war. the protirement picture of France May 1968's events was not that which was conveyed by the mass media but rather that which was made by the activism of cultured elite and media key figures when they took to the streets and supported the student's activism and reinforced its ideological, political and social tide.

That support was not called for by the mass media from either the written press or the audiovisual channels but it rather took shape thanks to link formed of various ideological cultural factors aside from the role of those pamphlets in stirring the importance of the students and-at a later stage-, the public demands.

In the latter case or the Arab Spring case for instance, we observe that the speed by which information is exchanged is extreme-near instant really-, we described it in this very context as the maximum velocity (Hidri, 1987), a speed allowing near instant level of interaction at any given time and the wildfire like spread of information and messages in all directions and across all cultural spaces.

It becomes apparent from these two cases that a single event is linked to a network of complex heterogenous elements posing as the root causes of its very existence and emergence and even dictating its course through the social environment, this refers to the very nature of the actor network as an environmental system for the social action which is not exclusively made by media unlike to what would be apparent to the fanatics about the role of media and social media networks.

Yet, nowadays mass media appears to be, in itself, the whole network, which gives an event its origins, and the root causes of its emergence.

This assumption is reinforced with the rise of the social media which are portrayed as the new manufacturer of the public opinion given their nature as personal-public medium allowing the emergence of the new influential players with significant power to shape the public opinion and given their status as a communicative system with an undeniable flexibility to achieve both denial and assertion simultaneously.

We come to understand at this point that the speed-or the velocity-actor: the factor of how fast information courses through the veins of society have quite the impact on our reading of actuality and assessment of events.

The works of the Arab media and communication, even the western ones did not pay much heed to this velocity factor: the factor of information transmission 
speed as mathematical approach to link valuable news and calculating their influence ratio:

The research materials which broached this point of view was limited to the boundaries of what was stipulated by the Shannon theory (Shannon, 1948), which eventually was of a great help in improving information transmission methods.

It also remains of note to mention the works of the physicist Leon Brillouin who leaned on the link between science and the media theory (Brillouin, 1956), and worked on establishing the systematic and procedural links between Shannon's Informational Entropy and Boltzmann's Statistical Entropy (Boltzmann, 1902). Robert Escarpit broached the subject of the entropy of information and -the information receiver-reaction as a duality to explain the pace of information transmission and their effect on the receiver (Escarpit, 1991), and despite the fact that he firmly believed in interdisciplinarity (Escarpit, n.d.), he was quick in warning about misusing and applying specific and sensitive scientific concepts out of their context.

This matter of-information-velocity-in its definition according to physics-did not occur to media scholars despite its value to gauge out a medium influence's level.

We previously worked on this aspect during the context of a study involving television and political media in Tunisia (Hidri, 1987), to better shed more lights on how media's influence develops whenever its transmission pace-or velocity -is varying and we observed that the factors of such an influence are indeed linked to the velocity by which information is exchanged between emitter and receiver:

The higher the velocity, the considerable the influence of the transmitted message for the simple reason that velocity is encapsulating transmission of events the moment they would occur resulting in the effect of polarization and whenever this velocity is moderate or lower as it is the case with the written press for instance the medium's influence levels are uneven and turbulent due to various complex invading factors such as: the pace of transmission, the space of transmission, the follow-up factor, the learning factor, the reading factor...etc. which leads gradually to polarization.

In conclusion, the media polarization as valuable mediatic effect most media key figures and communication scholars are vying to produce is actually produced-primarily thanks to-the velocity of the transmitted messages. The moment polarization takes hold reactions are bound to happen.

However, what makes the polarization of the social media more significant than that of traditional audiovisual media despite the same pace and frequency of transmitted messages between the two technologies? The answer is that the traditional audiovisual media have a high linear velocity, which does not allow instantaneous reactions. Social media on the other hand have a-nonlinearvelocity, which allows an infinite sequence of instantaneous reactions between 
its users.

In other terms, we describe the first linear velocity as a "controlling" velocity due to its origin stemming for an institutionalized media striving for socialization as it is proven with the collection of media's functions as defined by sociologists such as Wright Mills, H. Lasswel, J. Stoetzel, W. Schramm (Heinder, 2002).

As for the second velocity - that of social media-is according to us, a decentralized polarization velocity applied by all to produce meaning, transmitting it and exchange it and the primary factors for the existence of what is called among the scientific circles by the collective artificial intelligence (Levy, 1997), this extreme velocity running in every possible direction generating the highest polarization values ${ }^{1}$ causing instantaneous progressive reactions made the social media networks the actual "new workshops manufacturers of the public opinion".

If we are to extract from this approach a math "formula" to better understand the influence of the communicative system of the-social media-networks and raise awareness of their value as a public mediatic space with the power to shape ideas into an active force of society:

So if we are to assume that it is the media polarization level, which turns ideas to an active force within a social environment and that polarization generating reactions while being affected by a nonlinear velocity of transmission our equation would appear as:

Media Influence level $=($ polarization value + reactions value $) *$ velocity

$$
F=(X+f(X)) \cdot v
$$

Given:

F: Media Influence level

$X$ : Polarization value-unknown variable

Y: Reaction value-unknown variable

V: Velocity

$F(x)=y$

An equation revealing the existence of a multipole magnetic field within the social media networks, a field empowered by high magnetic force to generate polarization for every pole-every user of the social networks-is actually the charged body generating attention this techno-social system with its magnetic proprieties remains the strongest foundation of the new public mediatic space encapsulating the very formula capable of producing power.

Within this scope, it is imperative that we further study the issues of media and communication outside the boundaries of media itself.

The purpose here is to take advantage of what other fields of knowledge have to offer for a better understanding of the subject of this study. We would often stumble on the fact that many of the concepts and scientific terms in many of the

${ }^{1} 46 \%$ of the world's population use social networks, or 42.3 billion users, on 4.7 billion people. Source: http://www.blogdumoderateur.com/. 
literary works of the media and communication are actually derived from Physics and Math and Natural Sciences and were applied after juicing them out of their numeral mathematical properties.

These concepts offered new perspectives to study the media issues and enriched the already existing theories of media and communication.

The dialectic-for instance-of affirmation and nullification which we are about to study its structure is calling for an Interdisciplinary study of this new media a study that must derive its substance from the scientific concepts of physics and Math for this new media is not merely a field to be explored only by the means of technical, linguistic and social tools and concepts. It is rather a dynamical system subject to the laws that govern all dynamical complex systems which dragged us to point out its nature of chaos - again chaos as defined by the laws of physics (Hidri, 2012).

This dialectic of affirmation and nullification is revealed when we realize the velocity by which it runs and whenever we discern the level of its polarization and reactions.

For what gives social media their public opinion shaping power, as we explained with the Math formula mentioned above, is not only their affirmation and nullification proprieties but also the fact that they run with a nonlinear exponential velocity generating a progressive polarization stirring in their wake an infinite cyclone of reactions.

\section{Conclusion}

It remains crucial to note, in the light of what was mentioned above, that the media studies have to raise above the paradigm of oversimplification based on descriptive research papers and public observations filed with modeled conclusions and dim faded numbers that would provide no answers and bring nothing new to science.

The scholars of this field are called upon to broach the subject and the problematic of media and communication with a clear open mind towards all fields of science that would help establish new interdisciplinary and epistemological foundations to the media and communication science.

We are of mind to take full advantage of what the laws of Kinect energy and Dynamic Physics and the principles of thermodynamics have to offer to a better and closer understanding on how information is moving and converted from and inner concealed force to an active force of society.

Is information so different from the thermal energies within an organic body? Do information not dwell in social bodies and courses through its veins with the velocity predetermined by those who communicate and dissipates slowly the longer it spreads further? Is this velocity not relative? Different from one social body to another?

Can we not assume that internet is now a techno-cultural model of a dynamical system similar to the dynamical systems described in physics, chemistry and 
Math distinctive with their interacting components?

This level of interdisciplinary between various fields of knowledge calls for a reform of the ways of research thinking methods and theoretical tools applied so far in the field of media and communication to engulf the scientific oversimplification which taking strong roots within the Arab academic fields.

We should embrace with a receptive mind are those, in addition to human and social sciences, those of Physics both theoretical and quantitative to integrate the time proportions and equations so they would be of use in the field of media and communication.

The study of time aspects is actually the missing link in most of the communicative and media studies: the link that would help decipher the linguistic, physical, philosophical and narrative puzzles and many more.

The "game" of communication in the social networks is "game" played within the scope of time how then we would assume to observe and study it outside time's scope?

\section{Conflicts of Interest}

The author declares no conflicts of interest regarding the publication of this paper.

\section{References}

Adorno, T. W., \& Horkheimer, M. (1944). Dialectic of Enlightenment. New York: Social Studies Association, Inc.

Al-Masseddi, A. S. (1986). Linguistics and Its Scientific Foundations. Tunisia House. (In Arabic)

Abdullah, I., Al-Ghanmi, S., \& Awad, A. (1990). Knowledge of the Other. Lebanon: Arab Cultural Center. (In Arabic)

Aafia, M. N. (1998). Modernity and Communication in Contemporary Monetary Philosophy. The Habermas Model 4. Africa East, 1998, p. 109. Based on translation works of Henri Lefebvre. (In Arabic)

AlSayed, A. M., \& Hidri, A. Z. (2006). Matrix Terms and Concepts in the Introduction of Ibn Khaldun. Zallaq: University of Bahrain. (In Arabic)

Boltzmann, L. (1902). Leçons sur la théorie des gaz. Paris: Gauthier-Villars. (In French)

Brillouin, L. (1956). Science and Information Theory. New York: Academic Press.

Castells, M. (2006). Emergence des "médias de masse individuals". In: Les médias entre les citoyens et le pouvoir, World Political Forum, San Servolo, 23-24 Juin 2006. (In French)

Callon, M., \& Ferrary, M. (2006). Les réseaux sociaux à l'aune de la théorie de L'acteur-réseau. In: Sociologies pratiques/2 (No. 13, pp. 37-44). (In French)

Durkheim, E. (1893). De la division du travail social. Paris: Félix Alcan. (In French)

Durant, J.-P., \& Weill, R. (1997). Sociologie Contemporaine. Paris: Vigot. (In French)

Escarpit, R. (1991). L'information et la communication: Théorie générale. New York: Hachette. (In French)

Escarpit Robert (n.d.). https://en.wikipedia.org/wiki/ 
Fakhoury, A. (1990). Currents in al-Shamiya (p. 108). Beirut: Dar al-Taliah. (In Arabic)

Fiske, J. (1932). Introduction to Communication Studies. Studies in Communication, London and New York: Routledge.

Gul, M. Z. (2015). The Success of the Justice and Development Party in Turkey. Victory of a Nation and a Victory of the State, Al Quds Al Arabi, 3 November 2015. (In Arabic)

Hidri, A. Z. (2012). The New Media Order and Chaos (p. 88, 89). Dar Saher Publishing House. (In Arabic)

Hidri, A. Z. (2012). The New Media Order and Chaos (p. 92). Dar Saher Publishing House. (In Arabic)

Hidri, A. Z. (2012). The New Media Order and Chaos (p. 97). Dar Saher Publishing House. (In Arabic)

Hidri, A. (1987). Information et Espaces d'Information, R.T.C, No 13.

Hidri, A. Z. (1987). L'Information Politique Télévisée en Tunisie, Université de Bordeaux III. (In French)

Heinder, F. (2002). Une introduction aux fondements théoriques de l'étude des médias, Editions du Cefal, Belgique. (In French)

Ibn, K. (n.d.). Muqaddimah (Translation by Rosenthal, F., p. 59). (In Arabic)

Ibn, K. (n.d.) Muqaddimah (pp. 59, 60). Ibid. (In Arabic)

Jabbar, M. (2016). Turkey Social Media Fails the Coup, Al-Khalij Online, July 16. (In Arabic)

Kant, E. (1993). Critique de la faculté de juger, transl by Alexis Philonenko, Librairie Philosophique, J. VRIN, Paris.

Latour, B. (2007). Reassembling the Social, an Introduction to Actor Network Theory. Oxford: OUP.

Levy, P. (1997). L'intelligence collective: Pour une anthropologie du cyberspace. La Découverte. (In French)

Lam, A. (2012). From Arab Spring to Autumn Rage: The Dark Power of Social Media. https://www.huffingtonpost.com/andrew-lam/social-media-middle-east-protests-_b_1 881827.html

Moscovici, S. (1984). (sous la Direction), Psychologie Sociale, Chap. 7, Les Décisions en groupe (p. 216, 217, 218). P.U.F. (In French)

Munford, L. (1950). Technique et Civilisation, Ed. Seuil. (In French)

Novalis (1975). Euvres complètes, Paris, Gallimard(Volume 2, p. 66). (In French)

Shannon Claude, E. (1948). A Mathematical Theory of Communication. Bell System Technical Journal, 27, 379-423 and 623-656.

Weber, M. (1964). L'éthique protestante et l'esprit du capitalisme, Plon. 32. Web Marketing Conseil Report Juin 2016. (In French)

http://www.webmarketing-conseil.fr/classement-Reseaux-sociaux/

http://www.huffingtonpost.com/andrew-lam/social-media-middle-east-protests-_b_18 81827.html 